\title{
Woman Language: Features and Historic Change
}

\author{
Liwei Zhu \\ Tianjin Polytechnic University, China
}

\begin{abstract}
This paper first briefly looks at the previous studies done on female language from 1970s till now. Then it makes a brief analysis of some of the distinctive features of female language. Explanations about the reasons as to why these feature exist are offered from the physiological, psychological, social historical and social cultural standpoint. Finally, some changes about the woman language in recent years are expounded.
\end{abstract}

\section{Index Terms - woman language, Women's Movement, language change}

\section{Literature REVIEW ON WOMAn LANGUAGE STUdy}

The research on woman language is inaugurated by the publication of Robin Tolmach Lakeoff's book Language and Woman's Place in 1975, and it has long been reckoned as the beginning of the linguistic subfield of language and gender studies. After her initial observation, many other efforts have been made to enhance the study in this field. Here I want to mention some of the key influential contributions that have been made during these four decades.

Due to the popularity of radical feminism in 1970s, scholars located the woman language within historical context both within language and gender research and within feminist scholarship.

Sally McConnel-Ginet who is active in feminist, gender and sexuality studies makes a research on how ideologies are constructed through language and points out the fundamental relationship between subjectivity, stance and language.

Janet Holmes, the New Zealand linguist, through drawing on several linguistic corpora, notifies the central role that woman language plays in the politeness theory within linguistics, a role often overlooked by scholars who miss the connection between the gendered linguistic features---politeness and power.

There are also attempts to study woman language from inter-culture communication. Deborah Tannen discusses the importance of cultural differences in woman language. She proposes the genderlect theory and argues that gender is fundamentally a component of conversational style, along with ethnicity, region, age, class, and other factors.

Some scholars focus on exceptional speakers in addition to those who conform to gender ideologies. Kira Halls, the linguist and anthropologist, shows that there are some men, who remove themselves from structures of power also use feminine linguistic practices (hippies, gays and academics). Thus "women's language" is not fundamentally about gender but more basically about the displayed lack of power. By this, she locates the relationship between language and gender within the framework of power.

A different relationship between woman language and power is further explored by Jenny Cook-Gumperz (1977). She demonstrates the ways in which preschool girls experiment with and against powerful language. As a little girl learns to become a "lady", she also learns how to use language strategically, though not always successfully.

Shari Kendall (1999) in her research addresses the place of mothers in gendered language socialization. She notes the difference between the roles that a mother and father assume in interacting with their daughter at dinner time.

The woman language research extends as far as the technological area. Susan C. Herring's extensive research (1999) on gender and computer-mediated communication poses a contrary to the "technological determinism" of some feminists, which holds that cyberspace renders gender invisible and that there are sharp gender inequities in cyberspace.

There are also some linguists who notify the diversity of ways that women use language. Judith Mattson Bean (2006) considers how professional woman negotiates gendered expectations with her public role. They describe how the powerful women report their use of profanity to express authority and strong emotion but mitigate their self-description by using hedges. Thus, they conclude that woman identity is more a matter of social attribution and less a matter of choice---that's to say, gender identities are culturally constrained.

The research is also addressed towards a group of speakers who must negotiate both racist ideologies and gender stereotypes. Marcyliena Morgan (2005) demonstrates how features of "woman language" characterizes the racial subordination and shows how African American women today exploit and reject elements of white "women's language" in indexing their identity. Mendoza-Denton (2011) points to her own research on class, gender and ethnicity, focusing on how recent-immigrant, working class Mexican girls confront the stereotype of cultural conservatism and linguistic conservatism.

What has been mentioned are the chief achievements attained since 1970s. The range and diversity of the research on woman language continue to offer a rich theoretical basis for new work on the relationship of language, gender and sexuality in social life. These researches suggest that there is still much work remains to be done on the feminist linguistics and female culture study.

\section{Features of Woman Language}


Before this issue is deeply explored, it is necessary to analyse the following pairs of sentences.

A1: Gee, this hat is so lovely.

B1: This hat is not bad.

A2: Oh dear, you've put the peanut butter in the fridge again.

B2: Shit, you've put the peanut butter in the fridge again.

A3: You know, I really sort of hate driving because it's rather boring.

B3: I hate driving because it's boring.

Even people without linguistic knowledge will easily and definitely classify A1,A2,A3 as the typical woman language; while B1,B2,B3 are the man language. Some clues exist here, upon which people base their conclusions. Woman language is a lot different from man language with its unique characteristics.

The research on woman language can be traced back to 1664, when several features of woman language had been taken notice of by some anthropologists. As early as 1920 s, Otto Jesperson pointed out that woman tried their best to avoid rude and aggressive expressions in their verbal communication. (Xu, 1997) However, this topic hadn't been widely explored until 1960s when feminist movement came into life and reached its peak. Under this huge wave, American linguist Robin Lakeoff proposed the term "woman language" in 1973 and two years later she published her groundbreaking work Language and Women's Place which triggered a wide-spread interest among linguists as well as other researchers in topic on woman language. Her research has laid a corner stone for all the future investigation on this topic.

In some countries or areas, women use their language differently in term of phonology, morphology and syntax. They even possess their own language, with Nvshu in China as a typical example.

Phonological differences between speech of men and women have been noted in a variety of languages. In Gros Ventre, an American Indian language of the northeast United State, women have palatalized velar stops. For example, female says "kjasta", male says "djatsa". In a northeast Asian language, Yukaghir, women have /ts/ and /dz/, differing from men's $/ \mathrm{tj} /$ and $/ \mathrm{dj} /$. In Bengali men often substitute $/ 1 /$ for initial $/ \mathrm{n} /$; while women do not do this. Likewise, in a Siberian language, Chukchi, men but not women, often drop /n/ and /t/ when they occur between vowels, e.g. female nitvaqenat and male nitvaquat. School girls in Scotland apparently pronounce the " $\mathrm{t}$ " in words like "water" and "got" more often than school boys, who prefer to substitute a glottal stop. In Koasati, an American language spoken in southwestern Louisiana, among other sex-linked differences, men often pronounced an "s" at the end of verbs but women did not; for instance, male says "lakaws" and female "lakaw". In Japanese language, similarly, for the same character "ga", women and men pronounced differently. Women say /na:/, while men say /ga:/. However, there's also a change over for young women to pronounce "ga" as /ga: /.

There are certainly gender-related differences in word choice in various languages. Japanese women demonstrate their linguistic traits when they speak, for example, by the use of a sentence final "ne" or another "wa". In Japanese, too, a male speaker refers to himself as "boku" or "ore" whereas a female speaker uses "watashi"or "atashi".For example, if a man says "boku o chia o nomu"(I will drink tea), a woman should say "atashi o chia o nomuwa". Children learn to make these distinctions very early in life.. In polite conversation, a female speaker of Thai refers to herself as "dichan" whereas a man uses "phom". In Thai, too, women emphasize a repeated action through reduplication, ie, by repeating the verb, whereas men place a descriptive verb, "mak", after the verb instead. The Yana language in California contains special forms for use in speech by woman.

The differences mentioned above are more or less conventionalized historically. If the languages are used cross-genderedly, people in that culture will render it grammatically inappropriate.

Besides what have been mentioned, Robin Lakeoff in her book Language and Women's Place proposed several features of woman language and she also provides some insightful discussion related to them. The data on which she based her claims have been gathered by introspection. She has examined her own speech and that of her acquaintances and has used her own intuitions in analyzing them.

Some anthropologists and sociolinguists who prefer to use the data-gathering techniques, such as the recording of random conversation may object to these introspection methods. Yet, later research results have shown that most of these so called dubious introspections proved to be surprisingly correct and accurate. Although Lakeoff's conclusion about woman language features is not all inclusive, it's of great significance in pointing out for the further research in this area. Just as what has been said, woman language shows up in all levels of the grammar of English.

Generally speaking, woman language is different from man language in three aspects.

\section{A. Specialized Vocabulary}

Compared with man, woman tends to use more specialized color terms. For example, they will use mauve or lavender instead of purple. "... words like beige, aquamarine and so on are unremarkable in woman's active vocabulary, but absent from that of man..." (Lakeoff, 1975, P73)

According to Lakeoff, woman's discrimination of color might be attributed to women's tender feelings and high sensitivity. "A clue is contained in the way men in our society view other 'unworldly' topics, such as high culture and church, as outside the world of men's work, relegated to women and men whose masculinity is not unquestionable. Men tend to relegate to women things that are not of concern to them, or do not involve their egos..." (Lakeoff, 1975, P43) This means that since women are not expected to make decisions on important things, they focus their energy on some 
noncrucial matters as a comfort. Compared with this explanation, most feminists believe that women discriminate color terms better because they are more sensitive.

Another theory can also prove this point. According to the Sapir-Whorf's cultural relativism, the evolution of color terms can reflect the level of a culture's development. The cognitive psychologists are now exploring into the issue about whether woman's psychological world is more developed than that of man's. Eleanor Rosch, through many experiments put forward the "prototypical theory" and ultimately formed a proposition: man and woman have the same cognitive feature in terms of color sense, hue discrimination and color codification. In addition to this, many researches also testified Lakeoff's view. Not only do women like employing the fancy color terms, but also they probably have a larger and richer color corpus. However, there are some issues remained to be explored as to how women's universal advantage in language acquisition is shown through their learning of color terms and what the statistical differences of color code information storage, procession and extraction are.

\section{B. Milder Expletives}

In Lakeoff's book, the milder expletives are also called "weaker" expletives contrasting to man's "stronger" expletives. For example, when man uses "Dam it" or "shit", woman always uses "Darn!" The difference between using "shit" or "dam" as opposed to "dear" lies in how forcefully one says how one feels. "...choice of particle is a function of how strongly one allows oneself to feel about something, so that the strength of an emotion conveyed in a sentence corresponds to the strength of the particle." (Lakeoff, 1975, P44)

It might be asserted that male is more emotional than female. However, it's neither what we feel in our daily life nor can it be supported by our intuition. Quite contrarily, women always are regarded as more emotional. They swear or curse less because they are socially unacceptable. An English proverb can offer an explanation: A whistling sailor, a crowing hen and a swearing woman ought all three to go to hell together. Lakeoff also pointed out that it's inappropriate to use such trivial particles as "goodness" "oh, dear" in a very serious situation. For example, you can't say, "oh dear, my baby is kidnapped." or "Goodness, my hair is on fire!", unless you are joking.

\section{Empty Adjectives}

There are adjectives that can be used by both sexes to show their approbation or admiration for something. But some adjectives are largely confined to women. Here is a list:

$\begin{array}{ll}\begin{array}{l}\text { neutral } \\ \text { great }\end{array} & \begin{array}{c}\text { women only } \\ \text { adorable }\end{array} \\ \text { terrify } & \text { charming } \\ \text { cool } & \text { sweet } \\ \text { neat } & \text { lovely }\end{array}$

The column on the left are some neutral terms which are used by both sexes; the terms on the right column are, in most cases, restricted for women.

In Chinese, there are also some words which are mostly restricted to women, for example, "Wasai"(Wow) "Hao piaoliang"(Gorgeous). What invariably happens is that when a man uses the words solely reserved for woman, he'll be laughed at and this sometimes could even damage his reputation.

However, it shouldn't be inferred from this that a woman's use of "woman's words" is without its risks. For instance, if a woman wants to be a chief executive, she should say "What a terrific idea." instead of "What a divine idea". What this implies is that woman, if she wants to move into higher position, shouldn't speak like a woman, because, according to Lakeoff's explanation, the empty adjectives like "divine" are so trivial that they don't deserve any attention at all. “...women's language suggests that concepts to which they are applied are not relevant to the real world of (male) influence and power". (Lakeoff, 1975,P44)

As it has been mentioned, if we say woman's use of milder expletives shows that she doesn't have strong feelings, then the fact that she can employ more adjectives show that she does have strong feelings. Is this a kind of paradox? It can be justifiably said, not showing any bias toward either of sex, that man and woman both have strong feelings which are usually expressed in quite different situations as well as in different manners. Woman is more easily moved than man. When she is happy or depressed, she likes using these empty adjectives; while man is more apt to pick up a temper, hence he swears or curses more frequently and heavily than woman when he gets angry.

\section{Frequent Use of Tag-question}

There is no syntactic rule in English that only women may use. However, there's one rule that women will use in more conversational situations than men. This is the rule of tag-question formation.

Tag question is mid-way between an outright statement and a yes-no question. It's less assertive than the former, but more confident than the latter. It is used when the speaker is not quite sure about the claim he made. "A tag gives the addressee leeway, not forcing him to go along with the view of the speaker." (Pride, J.B, 1986, P248) There are some conditions on which the tag question can serve as a way of establishing conversation with others. One of the conditions is that when there is no uncertainty about the truth, in other words, the speaker doesn't need confirmation from the listener, the tag question might be used, for example, "Sunny day, isn't it?" Apart from this, there are other possible interpretations of tag question. One of them is that the speaker has already had a definite opinion in his mind, but he's 
unwilling to state it baldly. "These sentence types provide a means whereby a speaker can avoid committing himself...avoid coming into conflict with the addressee." (Pride, J.B, 1986, P245)

This sort of tag question, according to Lakeoff, is much more apt to be used by woman than by man. This claim has been testified by Dubois and Crouth (1975) The frequent use of tag question leaves such an impression on people: women are not sure of themselves and have no views of their own.

Besides this, there's also a peculiar sentence intonation pattern in woman language, which has the form of a declarative answer to a question, but has the rising inflection typical of a yes-no question, for example:

(a): When will dinner be ready? (b). Oh...around six o'clock?

Although (b) gives a very definite and clear answer, it seems that she is seeking for some kind of confirmation. This way of using language has brought much criticism. One likely criticism is that woman can't be trusted with any real responsibilities, since she can't make up her mind and isn't sure of herself. Here again, it can be seen that people always make hasty judgment on the superficial linguistic behavior that might have nothing to do with woman's inner characteristics. Speaking positively, the frequent employment of the tag questions and rising intonation prove woman's consideration for other's feelings and her willingness to get along well with others, which illustrates her preference of solidarity to competition.

\section{E. Super Polite Forms}

Women like using complex and indirect request, when they ask listeners for a favor. Here are five sentences of requests, each being different in terms of degree of politeness.

(a) Open the window.

(b) Please open the window.

(c) Will you open the window?

(d) Will you please open the window?

(e) Won't you open the window?

(a) and (b) are the "overt" imperative sentences which demand listener's straight obedience. It suggests the speaker's superior position to the addressee. Whereas (c) (d) and (e) leave space of consideration for the addressee. "The more particles in a sentence that reinforces the notion that it is a request, rather than an order, the politer the result is". (Lakeoff, 1975,P50) (a) is a direct order; (b) and (c) are simple request; (d) and (e) are compound requests. Obviously, sentences (c) (d) and (e) are the ones women prefer to use. This indicates that the more one compounds a request, the more characteristic it is of woman's speech.

\section{F. Standard Variety}

Women prefer using standard form both in syntax and in accent. Much of the evidence has come from the research carried out in Britain and America. The sets of data have provided have one extremely striking feature: women use form more approaching those of the standard. Consider the following figures about the use of non-standard multiple negation (I don't want no one.) in Detroit.

\begin{tabular}{l} 
PERCENTAGE OF MULTIPLE NEGATION USED \\
\begin{tabular}{|l|l|l|l|l|}
\hline & UMC & LMC & UWC & LWC \\
\hline Male & 6.3 & 32.4 & 40.0 & 90.1 \\
\hline Female & $0.0 \quad 1.4$ & 35.6 & 58.9 \\
\hline
\end{tabular} \\
\hline
\end{tabular}

This suggests that women are far more sensitive to the correctness of grammar than men.

In Norwich English, for example, the same sort of pattern emerges. The table below gives the percentage of non-RP-in' forms (e.g. walkin') used by speakers in different class and sex groups.

\begin{tabular}{|l|l|l|l|l|l|}
\hline \\
\hline & MMC & LMC & UWC & MWC & LWC \\
\hline Male & 4 & 27 & 81 & 91 & 100 \\
\hline Female & 0 & 3 & 68 & 81 & 97 \\
\hline
\end{tabular}

Once again, women use a higher percentage of standard form than men do. Some evidence has also shown the same result from Australia, South Africa and New Zealand.

\section{G. No Sense of Humor}

This feature of woman language might be the most obvious and least controversial one. Although lacking precise statistical evidence, I conclude from my own daily observation that most women are not adept at creating and understanding humor. People wouldn't fail to notice that when they are at school or in the work place, it's always the male students or male workers who like cracking jokes rather than females. Most of the stand-up comedians are man. There are historical and social reasons for women's lack of humor. It is known that when a joke is told or played upon a person, he or she will unavoidably be made fun of. Besides, the content of the joke in many cases is a little 
inappropriate. The society more often than not won't allow for this damage to morality. This ideology is more deeply rooted in the eastern culture. If a woman always cracks jokes or laughs, she'll be considered as unwomanish and wild. However, in the western countries like U.S, it seems more acceptable.

\section{H. The Cooperative Conversational Style}

Recent years, people begin to move their attention from the language structure to the discourse behavior in interaction. They try to solve the problem on a higher level and in a much more accurate way. According to the observations made by E. Aries on the social interactions, there are some conversational style differences between male and female speakers in the following aspects: (1) topic choice (2) quantity of speech (3) speech strategy

1. Topic Choice

Nearly all the investigations have shown that people of different genders talk on different topics. Generally speaking, women talk more about personal relationships and something that happened immediately, while men tend to talk something impersonal, and they keep distant from the present context of situation. For example, E. Aries (1996) investigated among the middle class people and discovered that women liked talking about personal things and they also liked to express their emotions. Men liked to talk about sports, politics and competitions. This claim has been proved by other researchers as well.

The topic choice differences are not only confined to adult people. Some investigations are made on the daily conversation of the white and black children. J, Brooks- Gunn and W, Matthews (1979) discovered that white boys liked exchanging information while white girls liked expressing their inner emotions. Black boys liked talking about their achievements while black girls liked discussing people's appearances or personal relationships.

2. Quantity of Speech

People for a long time have been holding such a stereotypical view that women talk more than men do. If you look up the words "babble" "chatter" "gab" "gossip" in the dictionary, you can always find a woman image in the example sentences. There is a Chinese saying: "Two women equal a thousand ducks", which describes women's talkativeness. However, what many people have noticed in the social interaction is quite contrary to what we expect.

In most of the places including the street markets, homes, restaurants, parties, meetings, sports events and so on, men talk more than women. This phenomenon is more obvious in the cross-gender conversations, for example, the conversation between couples, relatives, friends or colleagues. There is a funny story: A person had been watching a couple for 3 hours at a party and discovered that the husband spoke 5 times as much as his wife did. But after the party, when people were asked about their impression on this couple, they said the husband spoke too little and the wife was too talkative. This story illustrates that people tend to use different standards when they come to judge the speech behaviours of different sexes.

3.Discourse Strategies

Many studies (Coates, 1985; Tannen,1990) have shown us that the most significant gender differences in speech behaviors lie in the discourse strategies.

Generally speaking, during a conversation, women are more cooperative. Everyone takes turns to speak and they all have their chances. When a woman starts to speak, she always mentions what the previous speaker said and tries as much as she can to relate it to what she is going to say; she focuses on the conversational coherence and fluency. In this way, women usually spend a long time on one single topic. During the process of talking, they pay attention to the listeners' reaction and participation, which can be manifested by using the words like "we", "you" and "let's".

When others are talking, women will respond actively, they use "mm", "hmm" or "yeah" to indicate their attention. Occasionally, they'll offer some comments and raise some questions. They seldom interrupt others. Even if they do, they will add an apology like "Sorry to interrupt". When they want to express different opinions, their speech tends to be round about and hesitated. Some mitigating devices are often used like "sort of", "maybe" and "I guess". They hardly pose straightforward challenge to other people's opinions.

Compared with women, men tend to show strong competitiveness in their talk. They like to manipulate the topic and unwilling to give away "floor" to others, which always result in the fact that one person speaks too much, while others have no chances to speak. When men start talking, they seldom mention the previous speaker's talk. They just like to talk about what they want to say. Consequently, there is always a sharp switch of topic; also, there is not so much coherence in what they say. As to the listeners, men are not as concerned as women about their reaction and participation.

Many researchers (Zimmerman \& West, 1975; Coates, 1985; Tannen, 1990) also studied the speeches in the crossgender conversations. They discovered that in the cross-gender conversation, there are also significant differences between male and female and these differences are even larger. The differences have produced great effects on their communication.

Aries (1996) has shown that women are more willing to provide topics than men do, but men generally decide which topic should be talked on. For example, some linguists studied some family conversations by way of recording. They discovered that wives produced topics two times as many as husband did. However, most of these topics had to be given up for the husbands' lack of interest. Contrarily, although husbands proposed fewer topics, nearly all of them received warm responses from wives. Consequently, the cross-gender conversation is totally under men's control.

Why do men have more chances to speak? Why is it easier for them to talk what they like to talk about? Why can 
they control the whole process of talking? One of the reasons may be that women are more cooperative and more responsive. Another reason may be the differences of interruption between men and women. A number of researchers have done some surveys on the interruption of speech (Zimmerman \& West, 1975; Tannen, 1990). The result has shown that, whether they are adults or adolescents; men interrupt women much more than women interrupt men. In this way, women's opportunity to speak is lost due to men's frequent "aggression". When interrupted, women will keep silent more often than men do and the "silence" period lasts much longer. Undoubtedly, these differences will only enhance the "imbalance" in the cross- gender communication.

Men and women have different understandings about use of questioning in conversation. During the talk, women like asking questions to indicate their interest in conversation and they find it a good way of keeping the speaker's mood for talking. To put it another way, they consider questioning being a strategy of keeping and promoting communication. However, men question for information. Women's constant questioning is equally considered by men as an interruption of the conversation.

Similarly, men and women hold different views towards the "verbal aggressiveness" like swearing, shouting and cursing. Women take them as unfriendly behavior or a great damage to the normal conversation. Quite contrarily, men consider them unavoidable and necessary, or the conversation would be very boring.

These differences in speech behavior can not only cause the conflicts between men and women but also lead to the communication failure. Wives' complaint to husbands "Why don't you listen to me?" has become a widespread phenomenon around the world.

\section{Higher Pitch and Rising Intonation Patterns}

Women also differ from men in terms of voice quality, pitch and intonation patterns. The differences in voice quality; pitch and intonation patterns between sexes are due to the different biological structures, cultures, economic positions and communication backgrounds between man and woman.

Biologically speaking, women's speaking organ is different from that of men's. The vocal cords of the former are shorter and thinner and less elastic than the latter's. Women's average phonetic value is higher than that of men's. According to a survey made in America, men's voice frequency ranges from 78-698, while woman's ranges from 139-1108.

Beside these biological reasons, some social as well as psychological reasons also give rise to the differences of voice qualities between men and women. Speech signal is a complex acoustic activity, which can provide information about speaker's identity, individuality and emotions. In American English, there're two ways of pronunciation. When there's a vowel in front of a nasal: nasalization and non-nasalization. Austin (1962) discovered that nasalization is widely noted in the case of male rather than female. It's probably because nasalization will give an impression of roughness which is unsuitable for women's graceful image.

1. Higher Pitch

Pitch refers to the frequency of vocal cord vibration. The higher the frequency is, the higher the pitch is. Generally speaking, men's pitch ranges from 100-150H, women 200-325H. Many documentary materials have shown that high pitch is one of the remarking features of woman language. However, in the daily use of language, women often intentionally lower their pitch in various contexts. In people's mind, high pitch can hardly be related to serious topic. Not only is it the case in western culture, but also it is true in eastern culture. Almost in any of the society, high pitch reminds people of quarrelling or gossiping or even wordy while the low pitch means seriousness and dignity. Women's intentional lowing of their pitch can be best explained by the speech accommodation theory which suggests that addressors make certain modifications about their speech according to different contexts in order to accommodate themselves appropriately to the situations.

2. Rising Intonation Pattern

There are some gender-differentiated intonation patterns in English. Coming to 1970, studies in this area came up one after another. These researches generally demonstrated three points: first, psychologically, women's emotion is more outward, so their intonation pattern varies much more than men. Secondly, in societies, man's instrumental feature is emphasized while woman's social/emotional feature is more emphasized than their instrumental feature, which gives rise to the differences in the outer linguistic form between men and women. Last, in society, women lack sense of security and strong determination, so they like using the rising intonation.

\section{REASONS OF THESE FEATURES}

\section{A. Physiological Reasons}

Physiologically, women are different from men. Some scientists recently made an acclamation that they have found more statistics to prove that women speak more than men. This evidence has consolidated people's general impression on women. It is said that women's emotion is affected by endocrine hormone. Consequently, their emotion variation is bigger than men's, especially in its exuberating period, like before or after the menstruation.

All these explanations are intended to support one viewpoint: women speak much more than men, which, as has been mentioned earlier, is quite contrary to the fact. Is this a paradox? It might be explained in this way: women have strong willingness to speak; they like speaking and also are good at speaking. However, they have no chance to speak for the 
reason that they are most of the times suppressed by men, especially in the public domain.

\section{B. Psychological Reasons}

\section{Lack in Competitiveness}

Most of women, especially women in the conservative areas are content with what they are. Unlike men, they don't want to be the best in everything. What they are concerned about is how to establish a good relationship with others rather than taking the lead in the group. When there's conflict, they're in most cases willing to make a compromise. So when women participate in the conversation, they are more willing to take on a supportive role instead of playing the central role. They would rather give up the floor than pick up the fight with other speakers.

2. Lack in Confidence and Sense of Security

People often hear women say 'Oh, dear! What shall I do?' They often question their own ability to handle difficult situations, or even the things they are adept at. Even if they feel sure about something, they will not take a venture to do it or to speak it out. Before making any real decision, they always like asking somebody else for advice or for conformation. Very rarely can we hear a woman say an absolute "Yes" or "No". Their indeterminacy is shown in the sentences they use, for instance, "He's probably right", "I kind of like this decision.", "John is coming back, isn't he?" However, if considered in a positive way, women's lack of confidence can also be reckoned as modesty, which is their remarkable virtue as females. There has always been something that they find in need of improving. Hence, there is always room for change in what they have just said. That's to say, if they want to take back their words, people could hardly be able to find fault with them.

3. Higher Sensitivity

It's widely acknowledged that women's feeling is tender and exquisite. They can notice every tiny little thing men ignore and try to make sense of it. To them, words usually don't mean what they appear to mean. Thus, one should by no means take what she says literally. When they send out an invitation, ask for a favour or express a viewpoint, they usually do it in a roundabout way instead of doing it straightforwardly. There's always implied meaning in what they say. Sometimes, people even have to rack their brains to discern the implied meaning. That's why quarrels frequently happen between couples. Women's sensitiveness can lead to men's misunderstanding.

Here are some interesting examples to illustrate woman's usual implied meaning by what they say:

$\mathrm{No}=\mathrm{Yes}$

Yes $=$ No.

Maybe=No.

I'm sorry= It's you who should have felt sorry.

Go on with your own things= Please stop.

You are mannish= you should shave your beard.

This kitchen isn't good enough $=$ We need a new house.

Do you love me? = Get prepared psychologically, I want something expensive.

In a minute $=$ you'd better go to watch $\mathrm{TV}$ for an hour.

Another example is given to show women's tactfulness in their speech. If a lady past her prime time is asked about her age, she always answers, for example, "I have passed the age when I believe that man will change" or "I have passed the age when I want to get married."

\section{Social Reasons}

\section{Social-historical Reasons}

In the primitive society, survival is the most important in human life; people attached great importance to child bearing, so women played a dominant role in social and economic life. They took on important tasks such as hunting and ploughing. Their social status was much higher than that of men. However, as society gradually developed, due to the rough living environment and primitive manner of production, physical power and physical labour had been the primary means for human beings to fight against nature. Consequently, men with strong physical power, were pushed to the leading position. Since then, men have begun to undertake the heavy labour work. As the living style changed, there came into popularity of such an ideology: "The stronger, the superior; the weaker, the inferior." Male and female formed different experiences and psychological features in their respective working domain, which enhanced the polarization of personality trend and social status, which in turn gave rise to the conversion of social relation. This led to the consequences that patriarchy and andocentrism were consolidated both as a social order and a social convention. Men had become the representative of human civilization and the dominator of human society; contrarily, woman had to slide into the subordinate position and had to take on the supportive role. They hadn't their own voice and their own individuality. They even hadn't their own names.

In today's society, patriarchy has become a pretext to safeguard authority and social order. The gender discrimination has been entitled such good names as "social morality" and "social convention", which mostly tell a woman what's right and what's wrong. Society requires woman's behaviour to be different from that in man's society and culture. Women are given a set of different teaching based on their gender. Once their sex is determined physiologically, their names as well as clothing are different from men's. They are expected to become gentle and docile. If their behaviours didn't adhere to social conventions, they would be reproached, repelled or even punished. 


\section{Social-cultural Reasons}

In both eastern and western countries, the religions and languages contain a great number of stories about women's degeneration. In the Christian Bible Old Testament---Genesis: Eve disobeyed God's order and ate the forbidden fruit, thus was driven out of the Garden of Eden. She is obviously the source of human's original sin. In the Greek myth, Zeus, in order to revenge Prometheus, who stole fire from Olympus, created Pandora to send disasters to human world. Also, in the war of Troy, two countries fought for decades for the most beautiful woman in the world---Helen. So there's a proverb goes: No war without woman. In ancient China, two kings got so addicted to the great beauty of women that they couldn't be able to deal with state affair.

Here, in very general terms, at various times throughout history, all the female and male images in the legendary not only reflect the culture and social customs, but also have a huge impact on the ideology of later generation.

\section{Woman Language Change}

One of the major functions of language is that it serves as a tool of communication. Hence, language is closely related to our society and it changes and develops with the development of human world.

For woman language, it has changed considerably and will be changing in the future. So when efforts are exerted to make people believe the features of woman language mentioned early on, it's no strange case that they will raise controversies. Although we are not feminists, yet in the world today, we find these traditional views on woman language are not as justifiable as it was before. It's an undeniable truth that more and more women are getting much tougher and diversified than before. That's to say, apart from the traditional features which are still the hallmark of woman language, new features have been making their ways into it. The followings are some changes that have taken place until now.

\section{A. More Cursing and Swearing}

More and more women are now beginning to employ the terms that used to be forbidden by the social morality. This becomes even more obvious among young women or female teenagers. The followings are some sentences drawn from the most popular American TV series---Friends.

Monica (a head chef in a New York restaurant): Are you nuts? We've got George Stephano poulor's Pizza. (Season 1 Episode 4)

Monica: George, baby, drop the towel. (This happens when George, the guy whom she is peeping, covering his private part)(Season 1 Episode 4)

Rachael: (the head of Ralph Lauren Company): Come on! You guys can pee standing up. (Season 1 Episode 4)

Phoebe (a masseuse): I just want to bite his bottom lip. (When Phoebe sees Rachael's new boyfriend Paul) (Season 1 Episode 4)

Monica: Oh, really? So why was I busting my ass to make this delicious thanksgiving dinner. (Season 1 Episode 9)

Rachael: Oh, yeah? Well unless you pushed a desk out of your vagina, not the same thing. (Rachael has just given birth to a baby) (Season 9 Episode 8)

Amy (Rachael's sister): You bitch! You just think you are so perfect. (Rachael's having a fight with her sister--Amy) (Season 9 Episode 8)

Languages in situational comedies are mostly based on real life conversations. From these conversations, we note that these women tend to employ a huge number of forbidden words like cursing or swearing. They don't even feel shy to show their desire for men through the language they use. These are the examples of women's discourse that is "testimonial" to their social power.

\section{B. More External Topics}

Women begin to include more external subjects into their conversations. With women's gradually coming out of their home and making their way into the public domain, they are no longer content themselves with the role of baby-carers or the housekeepers. More women especially the young girls are getting more and more interested in talking about Kobe Bryan and Kofi Annan.

The emergence of more women politicians serves as a great factor that contributes to women's ever-increasing concern about state affairs. Today, we have ever increasing number of women politicians coming up the political arena: Thatcher, Clinton, Rice, to name a few, which has denounced the traditional view that women are unfit for politics. The notion that women can do as equally well as men now seems to make more sense. Since women politicians and women athletes are making greater achievements, there's no reason why they couldn't talk of the great contributions they have made. In the chatting room on the Internet, many girls are enthusiastic about mentioning various sports championships and tournaments and international and national affairs. When we watch the monographic interview broadcasted on TV, women occupied much of the time period allocated to the interaction part with the audience. They gave their opinions, discussed and argued with the host on some specific issues of national or international interest.

Beside their great concern about politics and sports, professional women also like talking about their careers when they gather together, since working has been gradually becoming focus of their lives. In America, there are many sororities, whose members usually gather together at weekends and attend various activities. During these activities, they share their experiences with each other, working experiences being one of their favourite topics. One of the lesbian 
groups in Los Angeles called "Wonder Woman's Island" is composed of the most powerful women in American society. Some of them are chief executives; others are millionaires or successful businesswomen. They have no children to look after, no housework to do; they don't depend on men. Most of their topics are confined to art, history, philosophy, commerce and trade.

\section{More Straightforwardness}

Women begin to speak more straightforwardly than before. This tendency seems to be more obvious in western countries.

Lakeoff once said, "The speech heard in commercials or situation comedies mirrors the speech of television-watching community." (Lakeoff, 1975, P87) If it did not, it wouldn't succeed. Correspondingly, this constructed speech provides clues to sociolinguistic phenomena and can offer insights into the linguistic attitude of viewers. Lakeoff develops this point further when discussing the influence of the media, arguing that the stereotypical images are often more influential than statistics. Women seen on the media have many traits of women's language built into their speech, which has of course been constructed for them by a team of writers. Female viewers pick up on these traits and seek to emulate the characters in their turn. This circuit of influence and reaction is difficult to analyse without close scrutiny of media images.

In the past, women, when they wanted to say something that might cause inconvenience, embarrassments or hurts to other people's feelings, they would speak it in a roundabout way. Now, they are more likely to say them out straightforwardly and feel free to do so.

This is even more obvious when women speak to men. Based on personal experiences and some theories, there are probably three reasons.

First, according to the speech accommodation theory, one speaker will accommodate his or her speech style to the other speaker when they are holding a conversation. Men, who are considered to speak more straightforwardly, carry their masculine conversational style to women in the cross-gender conversation.

Second, men are less sensitive than women. They won't get hurt by what others say as easily as women. So when a woman is trying to tell another man something that might cause offence, she needn't have to take great care. Tannen (1996) have provided both theoretical and statistical justification for this.

Third, there's a Chinese saying: Different sexes are mutually attractive. Women feel more at ease to speak what they want to speak with their male good friends than female good friends. They can scold them; lose temper on them without causing anger on the other side. There are perhaps some challenges towards this claim. Therefore, it needs further clarification. Psychologically speaking, many women subconsciously treat their male good friends as someone they can rely on or feel much closer to. Harry and Sally in the American movie When Harry Met Sally are just two stereotypical images representing such cross gender friendships. The above assumptions are based on the examination of some of my acquaintances' speech. Those familiar with what seems to them more error proof data-gathering technique may object that these introspective methods may produce dubious results. However, to justify the intuition, it should be clarified that any procedure of researching is at some point introspective, and if we are to have a good sample of data to analyse, this will have to be elicital artificially from someone. What's more, it's usually believed that introspection sometimes produces better and accurate result than quantitative analysis.

Even in the most sex-differentiated countries like Japan, woman language is also changing. Zhao Rong (2001) argued that in Japanese language, gender-related differences are largely shown in the ending word of a sentence. For example, women scarcely used "da", which is a word showing certainty. They say "dameyo" instead of "damedayo". However, recent investigation suggests that more and more Japanese women now use "da". The frequency of this usage increases with the decreasing of age: aged 20-30: 52.6\%; aged 31-40:30\%; aged 41-50: 30\%; aged 51-60: 4.5\%.

In a random sampling done on the way of expressing the meaning "It's raining", the researchers chose "amedayo; ameyo; amedazo; amedazeyo; amedawayo" five ways. The first three are the male style; the last two are female style. The following table shows light on this issue.

TABLE 1

\begin{tabular}{|c|c|c|c|c|c|}
\hline $\begin{array}{l}\text { Word used } \\
\text { Age period }\end{array}$ & amedayo & ameyo & amedazo & amedaze & amedawayo \\
\hline $21-30$ & $92 \%$ & $31 \%$ & $9 \%$ & $3 \%$ & $5 \%$ \\
\hline $31-40$ & $81 \%$ & $63 \%$ & $4 \%$ & $3 \%$ & $13 \%$ \\
\hline $41-50$ & $51 \%$ & $74 \%$ & $2 \%$ & $2 \%$ & $22 \%$ \\
\hline $51-60$ & $19 \%$ & $83 \%$ & $0 \%$ & $0 \%$ & $37 \%$ \\
\hline
\end{tabular}

From the preceding statistics, we note that Japanese women born before the World War II mainly employ female language. For the women born in 1950s, the chance of their using male language increases; for the women born in 1970 s, most of them would use male language.

The result of the random sampling suggests that more and more females use male language in nowadays.

\section{REASONS FOR THESE CHANGES}


Linguistic change and social change go hand in hand. Thus, it's worth having a look at some factors which contributes to the great change of woman language through these decades.

\section{A. Improvement of Women's Social Status}

In the pre-historian period, there was no such problem as gender inequity. People's labour division is based on their physiological features. Women gave birth to children and got engaged in planting; men went out for hunting.

However, when human beings entered the feudal society, the ruling class began to advocate the superiority of male to female. Women's rights and talents were tramped. For instance, Confucius put forward "three cardinal guides and the five constant virtues" for women to abide by. After human race entered the capitalist society, women began to be more and more aware of their inferior position in society and started to demand for gender equity and equality. Thanks to the two waves of women's movements in 1960s and 1970s and women's constant struggle, they now have acquired nearly all types of basic rights they should have: voting rights, educational rights. They are no longer forbidden to work outside. They can be professors, doctors, lawyers, which used to be completely occupied by men. A huge number of women have gotten into the political arena. For the time being, women participate in all kinds of activities in areas like economy, culture, education, social charity work and so on. Li Yinhe (2000) mentioned the famous feminist Simone de Beauvoir's proposal of the three approaches for women to deal with their gender oppression. First, women should go out to the society to work. Second, women should become intellectuals. Third, society should be transformed into socialism to solve the conflicts between subject and object, self and others.

\section{B. Women's Movement}

Women's inferiority has its social and cultural reasons. The task of women's movement is to bring challenge to the present social order and try to change it. A clear concept of women's movement can be attained by briefly reviewing some historical events concerned about it.

In 1848, July 19th, the first American Women Right Conference was held in New York. The chief organizers Lucretra Coffin Motol, Elicabeth Cady Standin, Susan B Anthony were later called the "Mothers of Feminist Movement". Some historians labeled the opening of this conference as the beginning of American women's movement.

One activity deserves our special attention--- the "Consciousness Raising Movement" which had been extremely popular in the 60s and 70s. Women would get together and hold conversations; each week, through their personal experiences as daughters, wives, sisters, lovers, students and workers, they criticize the current social structure, which keep women silent and miserable. This activity reached its peak from 1970 to 1974 . Women who took part in the activity were engaged in every female-related topic and re-evaluated the mainstream cultural ideology through their personal experiences. Every woman in the group was encouraged to tell her emotional life and express herself. They were even encouraged to discuss their sexual life, desire and the significance of sex.

Generally speaking, feminists showed their great confidence in the second wave of women's movement. However, this confidence, through the resurgence of conservative force in $80 \mathrm{~s}$, declined. Yet, in the 21 st century, many new theories and schools are coming up continuously and are sneaking their way into every aspect of our life as well as the mainstream ideology.

\section{CONCLUSION}

Through many decades' study on the women issue by sociologists and sociolinguists, people began to know more about the language that women speak including its features and linguistic changes. Some features of woman language have testified people's general impression, while others are not. This paper, basing on Robin Lakeoff's book Language and Woman's Place, proposes several universal features of woman language, ranging from phonology, morphology, vocabulary, and syntax to conversational style. Language is closely related to our society. It changes and develops with the development of human world. The changes of woman language happen also because of some social, cultural and historical reasons, for example, the improvement of woman's social status and women's movement. All the achievements made on the study of woman language must be attributed to the women movement in 1960s and to the development of feminist theories whose theoretical approach provides us a solid base for researching the woman language.

\section{REFERENCES}

[1] Aries, E. (1996). Men and women in interaction. Oxford: Oxford University Press.

[2] Austin, J.L. (1962). How to do things with words. Oxford: Oxford University Press.

[3] Bean, J.M. (2006). Gaining a Public Voice: A Historical Perspective on American Women's Public Speaking. Speaking Out. 21-39.

[4] Brooks-Gunn, J. \& Matthews, W. (1979). He and She: How Children Develop Their Sex - role Identity. Englewood Cliffs, N J: Prentice-Hall.

[5] Cameron D. \& Coates J. (1985). Some problems in the sociolinguistic explanation of sex differences. Language and Communication .Vol.5 No.3. 143-151.

[6] Coates, J. (1986). Women, Men and Language. London: Longman.

[7] Cook-Gumperz, J. (1977). Situated Instructions: Language Socialization of School Age Children 1.Child Discourse, 103-121. 
[8] Dubois, B.L \& Crouch, I. (1975).The question of tag questions in women's speech: They don't really use more of them, do they? Language in Society. Vol. 4 No.3, 289-294.

[9] Hall, K \& Bucholtz, M. (1995). Gender articulated: Language and the socially constructed self. New York: Routledge.

[10] Herring, S.C. (1999). The rhetorical dynamics of gender harassment on-line. Information Society. Vol.15, No.3, $151-167$.

[11] Holmes, J. (2001). A corpus-based view of gender in New Zealand. Gender across languages: The linguistic representation of women and men. Vol.1, 115-136.

[12] Holmes, J. \& Miriam, M. (2003). The handbook of language and gender. Oxford: Blackwell.

[13] Holmes, J. (1995). Women, men and politeness. London: Longman.

[14] Lakeoff, R. \& James, C. C. (1993). Father knows best: The use and abuse of power in Freud's case of Dora. New York: Teacher College Press.

[15] Lakeoff. R. (1975). Language and Woman's Place: Text and Commentaries. Oxford: Oxford University Press.

[16] Li Yinhe. (2006). Feminism. Jinan: Shandong People's Press.

[17] Morgan, M. (2005). Hip-Hop Women Shredding the Veil: Race and Class in Popular Feminist Identity. South Atlantic Quarterly, Vol.104, No.3, 425-444.

[18] Pride, J.B. (1986). The Social meaning of language. Oxford: Oxford University Press.

[19] Rodolfo, Mendoza-Denton. (2011). Step Away From the Slur. Psychology Today. Vol.44, No.5, 52-53.

[20] Shari, K, \& Tannen, D. (1997). Gender and language in the workplace. In Ruth Wodak (ed.), Gender and discourse. London: Sage.81-105

[21] Shari, K. (1999). The interpretation of gendered spheres: A sociolinguistic analysis of mothers and fathers at work and at home. PhD diss. Georgetown University.

[22] Tannen, D. (1990). You Don't Understand: Men and Women in Conversation. New York: William Morrow.

[23] Tannen, D. (1994).The relativity of linguistic strategies: Thinking power and solidarity in gender and dominance. In Deborah Tannen (eds.) Gender and Discourse. Cambridge: Cambridge University Press. 256-261.

[24] Tannen, D. (1996). Researching Gender-Related Patterns in Classroom Discourse. TESOL Quarterly. Vol.30, No.2, $341-344$.

[25] Trudgill, P. (1986). Social identity and linguistic sex differentiation. Dialect and Language Variation. 395-402.

[26] Trudgill, P. (1972). Sex, covert prestige and linguistic change in the urban British English of Norwich Language in Society. Vol.1 No.2, 179-195.

[27] Wardhaugh.R. (2000). An Introduction to Sociolinguistics. $3^{\text {rd }}$ Ed. Beijing: Foreign Language Teaching and Research Press.

[28] Xu Lisheng. (1997). Gender-related differences in discourse. Foreign Language. No1:42-47.

[29] Zhao Rong. (2001). The masculinization of Japanese women's language. Foreign Language Education. Vol.22, No.6, 84-87.

[30] Zimmerman, D. H. \& West, C. (1975). Sex roles, interruptions, and silence in conversation. In B. Thorne et al. (ed.) Language and Sex: Differences Dominance. Rowley: New bury House. 168-182.

Liwei Zhu was born in Jilin, China in 1981. She received her M.D. in Foreign Linguistics and Applied Linguistics in Beihua University, China in 2006. Her research interests include applied linguistics, TESOL and English literature. 